\title{
Short-term outcomes of surgical myocardial revascularization on health-related quality of life: a validation of the Arabic MacNew heart disease questionnaire
}

Mohammad Abdallah ${ }^{1,2^{*}}$ (D) Shymaa Mamdouh ${ }^{3}$, Abdel-Hady El-Gilany ${ }^{3}$, Wael Abdel-Aziz ${ }^{4}$, Olfat Farag ${ }^{3}$ and Noha ElAdawy ${ }^{3}$

\begin{abstract}
Background: Impaired quality of life $(\mathrm{QOL})$ is common in coronary heart disease and is the major indications for coronary artery bypass graft (CABG) operations. This study aims to compare the QOL of patients with coronary heart disease before and after CABG surgery.

Results: A translated Arabic version of the Mac-New health-related QOL questionnaire was used to evaluate QOL improvement in 446 patients who benefited from elective CABG at Nasser Institute for Research and Treatment. There was a statistically significant improvement in physical, emotional, social, and global domains of QOL, as evaluated 3 and 6 months after surgery. Follow-up was $90.4 \%$ complete. At 3 months, multiple linear regression has shown that male patients ( $\beta=0.48, p \leq 0.001)$ and rural residence $(\beta=0.39, p \leq 0.001$ ) were significant independent predictors of improvement in physical QOL domain. While hypercholesterolemia $(\beta=-0.20,-0.49,-0.37,-0.46, p \leq$ 0.001 ), hypertension $(\beta=-0.29,-0.39, p \leq 0.001, \beta=-0.35,-\beta=0.35, p=0.001)$, and smoking $(\beta=-0.79, p \leq 0.001$, $\beta=-0.33, p=0.04, \beta=-0.69, p \leq 0.001, \beta=-0.47, p=0.005$ ) were significant predictors of worsening in physical, emotional, social, and global domains, respectively. At 6 months, low preoperative ejection fraction (EF) $\leq 40 \%$ was the strongest predictor of improvement $(\beta=0.54,0.49,0.44$, and $0.52, p \leq 0.001)$ in physical, emotional, social, and global domains of $\mathrm{QOL}$, respectively. But, peripheral vascular disease (PVD) $(\beta=-0.53, p=0.05, \beta=-0.81, p=0.005$, $\beta=-0.62, p=0.03, \beta=-0.76, p=0.008)$ and smoking $(\beta=-0.53, p=0.001, \beta=-0.42, p=0.01, \beta=-0.42$, $p=0.01, \beta=-0.41, p=0.02$ ) were significant predictors of worsening in physical, emotional, social, and global domains of QOL, respectively.
\end{abstract}

Conclusions: CABG surgery improved in all domains of QOL. Further studies are required to evaluate changes in $\mathrm{QOL}$ at longer period intervals.

Keywords: Quality of life, Coronary artery disease, Coronary artery bypass graft surgery

\footnotetext{
* Correspondence: dr.mohamedd84@gmail.com

'Department of Cardiothoracic Surgery, National Heart Institute, Cairo, Egypt 2Department of Cardiothoracic Surgery, Shebein Elkom Teaching Hospital,

Shebein Elkom, Egypt

Full list of author information is available at the end of the article
}

\section{Springer Open}

() The Author(s). 2020 Open Access This article is licensed under a Creative Commons Attribution 4.0 International License, which permits use, sharing, adaptation, distribution and reproduction in any medium or format, as long as you give appropriate credit to the original author(s) and the source, provide a link to the Creative Commons licence, and indicate if changes were made. The images or other third party material in this article are included in the article's Creative Commons licence, unless indicated otherwise in a credit line to the material. If material is not included in the article's Creative Commons licence and your intended use is not permitted by statutory regulation or exceeds the permitted use, you will need to obtain permission directly from the copyright holder. To view a copy of this licence, visit http://creativecommons.org/licenses/by/4.0/. 


\section{Background}

Coronary heart disease (CHD) has many adverse effects on different aspects of physical, psychological, social, and spiritual health [1]. Coronary artery bypass grafting $(\mathrm{CABG})$ is the treatment of choice for patients with atherosclerotic CHD. The benefits include relief of angina, improvement in the quality of life (QOL), and an increase in life expectancy in high-risk patients [2]. QOL is a multidimensional concept that includes an individual's physical, psychological, and social status; it is a sense of well-being which is due to satisfaction or dissatisfaction with different aspects of life which are important for an individual. Change in patients' QOL is one of the essential outcomes of CABG surgery [3]. The dimensions or subscales yield summary scores that constitute a profile of QOL and is a subjective patients' perception of their health and treatment and is a core concept "patient-reported outcomes" (PROs) of the patient's perspectives in epidemiological, health economics, clinical, and health services research [3]. Consequently, assessing the QOL is one of the debatable topics of recent decades in clinical research [4].

Generic QOL measurements include the Short Form Health Survey (SF-36), Sickness Impact Profile, and Nottingham Health Profile (NHP). The SF-36 and the NHP appear to have better content validity in the field of cardiac surgery because each covers energy/vitality and bodily pain, and appropriate if not essential aspect of cardiac surgery recovery for ischemic heart diseases and procedures. Disease-specific QOL measures include Duke Activity Status Index, MacNew Heart Disease Quality-of-Life Measure, Seattle Angina Questionnaire, Minnesota Living with Heart Failure Questionnaire; Heart-QOL [5]. MacNew Heart Disease QOL questionnaire was the most commonly used in different cardiac patients and was translated and validated into many languages (these are available at http://www.macnew.org/ $\mathrm{wp} /$ ) [6].

There is a dearth of knowledge about the effect of CABG surgery on patients QOL in Egypt. The study objectives were to (1) validate a translated Arabic version of the Mac-New health-related quality of life questionnaire; (2) assess changes in QOL after 3 and 6 months of CABG surgery; and (3) identify factors related to QOL changes after CABG.

\section{Methods}

\section{Setting and participants}

The study followed the STROBE cross-sectional reporting guidelines [7]. This is a descriptive follow-up study on CHD patients who underwent CABG surgery. It was carried out at the Outpatient Clinic of the Cardiac Surgery Unit of Nasser Institute Hospital for Research and
Treatment, Cairo, Egypt, during the period from May 2017 to July 2018.

A convenience sample (based on the time frame) of 446 patients underwent elective CABG surgery and fulfilling the legibility criteria during the study period were included. Only 43 patients (9.6\%) of patients were dropped out from follow-up at 6 months (11 deaths, 9 wrong mobile and/or address, and 23 did not reply after three calls in three consecutive days).

\section{Legibility criteria}

Eligible patients were all adult aged $\geq 18$ years diagnosed with ischemic heart disease (IHD) who underwent isolated elective CABG in patients. Patients should be fully conscious and accepting to participate in the study. Excluded patients were those in critical preoperative state, impaired consciousness, patients who were unable to complete the study tools (e.g., hearing impairment), and other concomitant surgeries (e.g., valvular surgery, CABG with valvular surgery, aortic aneurysm surgery).

The patients were interviewed during the study period at 3 months after CABG surgery and followed-up at 6 months postoperatively.

\section{Data collection}

Data were collected at 3 months with direct patients' interviews, from medical records and 6 months after surgery through telecommunications of patients via mobile phones to highlight further QOL changes. The Mac New Heart Disease HRQOL questionnaire is a selfadministered modification of the original quality of life after myocardial infarction [8]. It comprises 27 items which fall into 3 domains emotional (14 questions), physical (14 questions), and social (13 questions) dimensions. The score of every question was modified to be 3 Likert scale (1 to 3 ) instead of 7 Likert scales to be easier and understandable in our culture. Three are the best present conditions of QOL and one is the minimum score (the worst present conditions of QOL). The higher score in every domain means higher QOL. Each domain score is calculated as the average of the responses in that domain, and the tool also has a global HRQOL score which calculated as the average overall scored items. The questionnaire was forward translated into the Arabic language by two different translators and back translated to English to ensure linguistic validity. The questionnaire was validated by three experts in public health and two experts in cardiothoracic surgery. The content validity index for relevance and clarity of different items varied from 0.72 to 1.0 (a copy of the study questionnaire is available upon request from the corresponding author).

A pilot study was done on 10 patients (not included in the full-scale study) to test the reliability of the 
translated Mac-New Heart Disease HRQOL questionnaire. The Cronbach's alphas of emotional, physical, social, and total scale were found to be $0.87,0.96,0.92$, and 0.96 , respectively. The interclass correlation was 0.96 . There were no missing items. The ceiling effects of different items ranged from 0 to $20 \%$, while the floor effects varied from 0 to $30 \%$ for different items.

\section{Data collection approach}

Data were collected 3 months after CABG surgery by direct interviews with patients to include illiterate patients. However, at 6 months was collected by telecommunications as most the patients do not keep in the follow-up.

\section{Ethical consideration}

The study proposal was approved by IRB, authors' institution. Patients gave informed consent to participate in the study after assurance of data confidentiality and they have the right to withdraw from the study at any time.

\section{Statistical analysis}

The data were collected and analyzed using Statistical Package for Social Sciences (SPSS for Windows program version 22; SPSS Inc., Chicago, Il, USA). Cronbach's alpha was used to test the internal consistency of the construct. The floor effects, ceiling effects, interclass correlation were calculated. The change in QOL was calculated by the difference between score post-surgery and pre-surgical scores for each domain. Kolmogorov-Smirnov one-sample test was used to assess the distribution of quantitative data and found to be non-parametric. The quantitative data were presented as the median (maximum-minimum). Non-parametric tests (Friedman's test and Wilcoxon's sign test) were used whenever appropriate. Scores were long transformed through two steps: first QOL scores were ranked and then transformed through inverse distribution function. Normal (IDF. Normal) to have normalized ones [9]. Correlation coefficients were calculated using the parametric Pearson rank correlation coefficient. Significant correlations were entered into a linear regression model to evaluate the contribution of factors found to be significant in bivariate analysis in predicting the normalized QOL difference scores after 3 and 6 months of CABG surgery. $P \leq 0.05$ was considered statistically significant.

\section{Results}

Table 1 shows statistically significant improvement in all domains of QOL after 3 and 6 months of CABG surgery $(p \leq 0.001)$. More improvement was noticed in the physical and social domains than the emotional domain 6 months after CABG surgery (median scores were 3.0 and 3.0 vs. 2.93 , respectively).

Multiple linear regression after 3 months of CABG surgery shows that male sex $(p \leq 0.001)$ and rural residence $(p \leq$ 0.001 ) are significant independent predictors of physical QOL improvement. Education was a significant independent predictor for QOL improvement in emotional $(p=0.005)$, social domain $(p=0.03)$, and global domain $(p \leq 0.001)$, respectively. Hypercholesterolemia, hypertension, smoking, and gastrointestinal disease $(p \leq 0.001)$ were independent significant predictors for QOL worsening in all domains of QOL $(p \leq 0.001)$. While renal disease $(p=0.02)$ and cerebrovascular disease $(p=0.03)$ were significant independent predictors of worsening social domain of QOL (Table 2).

Multiple linear regression after 6 months of CABG surgery shows that low $\mathrm{EF} \leq 40 \%(p \leq 0.001)$ was a significant independent predictor of higher median difference scores of all QOL domains. However, peripheral vascular disease (PVD) was a significant independent predictor of lower median difference scores of all domains of QOL $(p \leq 0.05)$ (Table 3).

\section{Discussion}

The Arabic version of the MacNew heart disease questionnaire is both valid and reliable. The overall Cronbach's alpha is 0.96 . This is comparable to its version in other languages, e.g., 0.94 for French version [10], 0.90 to 0.94 for Danish, Norwegian, and Swedish versions, respectively [11], 0.93 for Korean version [12], and $0.95 \%$

Table 1 Comparison of scores of domains of quality of life before and after CABG

\begin{tabular}{|c|c|c|c|c|}
\hline Domain & $\begin{array}{l}\text { QOL before CABG (446) median } \\
\text { (minimum-maximum) }\end{array}$ & $\begin{array}{l}\text { QOL after } 3 \text { month of CABG (446) } \\
\text { median (minimum-maximum) }\end{array}$ & $\begin{array}{l}\text { QOL after } 6 \text { month of CABG (403) } \\
\text { Median (minimum-maximum) }\end{array}$ & $\begin{array}{l}\text { Significance } \\
\text { (Friedman's test) }\end{array}$ \\
\hline Physical & $1.64(1.00-2.07)^{\mathrm{A}, \mathrm{B}}$ & $2.93(1.00-3.00)^{\mathrm{A}, \mathrm{C}}$ & $3.00(2.29-3.00)^{B, C}$ & $\begin{array}{l}x^{2}=712.35, p \leq \\
0.001\end{array}$ \\
\hline Emotional & $1.71(1.00-2.07)^{\mathrm{A}, \mathrm{B}}$ & $2.79(1.00-3.00)^{\mathrm{A}, \mathrm{C}}$ & $2.93(2.00-3.00)^{B, C}$ & $\begin{array}{l}x^{2}=676.09, p \leq \\
0.001\end{array}$ \\
\hline Social & $1.77(1.00-2.15)^{A, B}$ & $3.00(1.00-3.00)^{\mathrm{A}, \mathrm{C}}$ & $3.00(2.00-3.00)^{B, C}$ & $\begin{array}{l}x^{2}=724.71, p \leq \\
0.001\end{array}$ \\
\hline Global & $1.74(1.00-2.15)^{A, B}$ & $2.81(1.00-3.00)^{A, C}$ & $2.96(2.15-3.00)^{B, C}$ & $\begin{array}{l}x^{2}=676.12, p \leq \\
0.001\end{array}$ \\
\hline
\end{tabular}

$\overline{\mathrm{A}, \mathrm{B}, \mathrm{C}}$ Significant difference between the corresponding times by Wilcoxon's test for paired comparison 
Table 2 Multiple linear regression analysis of independent predictors of physical, emotional, social, and global QOL-normalized difference score after 3 months of CABG surgery

\begin{tabular}{|c|c|c|c|c|c|c|c|c|}
\hline \multirow[t]{2}{*}{ Predictors } & \multicolumn{2}{|c|}{$\begin{array}{l}\text { Physical domain difference } \\
\text { score }\end{array}$} & \multicolumn{2}{|c|}{$\begin{array}{l}\text { Emotional domain difference } \\
\text { score }\end{array}$} & \multicolumn{2}{|c|}{$\begin{array}{l}\text { Social domain difference } \\
\text { score }\end{array}$} & \multicolumn{2}{|c|}{$\begin{array}{l}\text { Global domain difference } \\
\text { score }\end{array}$} \\
\hline & $B$ & $p$ & $B$ & $p$ & $B$ & $p$ & $B$ & $p$ \\
\hline Gender & 0.48 & $\leq 0.001$ & 0.50 & $\leq 0.001$ & 0.43 & $\leq 0.001$ & 0.49 & $\leq 0.001$ \\
\hline Age & & & 0.01 & 0.04 & & & & \\
\hline Residence & 0.39 & $\leq 0.001$ & 0.30 & 0.001 & 0.37 & $\leq 0.001$ & 0.36 & $\leq 0.001$ \\
\hline Education & & & 0.36 & 0.005 & 0.29 & 0.02 & 0.02 & 0.03 \\
\hline Diabetes & -0.20 & 0.05 & & & & & & \\
\hline Dyspnea grade & & & & & 0.51 & 0.003 & & \\
\hline Hypercholestermia & -0.20 & $\leq 0.001$ & -0.49 & $\leq 0.001$ & -0.37 & $\leq 0.001$ & -0.46 & $\leq 0.001$ \\
\hline Hypertension & -0.29 & $\leq 0.001$ & -0.39 & $\leq 0.001$ & -0.35 & $\leq 0.001$ & -0.35 & 0.001 \\
\hline Smoking & -0.79 & $\leq 0.001$ & -0.33 & 0.04 & -0.69 & $\leq 0.001$ & -0.47 & 0.005 \\
\hline Gastrointestinal disease & -0.44 & 0.003 & -0.63 & $\leq 0.001$ & -0.51 & 0.001 & -0.59 & $\leq 0.001$ \\
\hline Renal disease & -0.66 & 0.03 & & & -0.66 & 0.02 & & \\
\hline Cerebrovascular disease & -0.63 & 0.006 & & & -0.50 & 0.03 & -0.54 & 0.02 \\
\hline Constant & 0.145 & & 0.759 & & 0.121 & & 0.287 & \\
\hline$R^{2}$ & 0.23 & & 0.24 & & 0.22 & & 0.22 & \\
\hline F & 7.406 & & 8.063 & & 7.274 & & 7.157 & \\
\hline P & $\leq 0.001$ & & $\leq 0.001$ & & $\leq 0.001$ & & $\leq 0.001$ & \\
\hline
\end{tabular}

Coding of variables included in the model

0 was given for female, urban residence, low education, no diabetes, no hypercholestermia, no smoking, no hypertension, no gastrointestinal disease, no renal disease, no cerebrovascular disease, and low dyspnea grade (NYHA1- NYHA 2)

1 was given for male, rural residence, high education, diabetes hypercholestermia, hypertension, renal disease, gastrointestinal disease, smoking, high dyspnea grade (NYHA3-NYHA4)

Table 3 Multiple linear regression analysis of follow-up independent predictors of physical, emotional, social, and global QOLnormalized difference score after 6 months of CABG surgery

\begin{tabular}{|c|c|c|c|c|c|c|c|c|}
\hline \multirow[t]{2}{*}{ Predictors } & \multicolumn{2}{|c|}{$\begin{array}{l}\text { Physical domain difference } \\
\text { score }\end{array}$} & \multicolumn{2}{|c|}{$\begin{array}{l}\text { Emotional domain difference } \\
\text { score }\end{array}$} & \multicolumn{2}{|c|}{$\begin{array}{l}\text { Social domain difference } \\
\text { score }\end{array}$} & \multicolumn{2}{|c|}{$\begin{array}{l}\text { Global domain difference } \\
\text { score }\end{array}$} \\
\hline & $B$ & $p$ & $B$ & $p$ & $\bar{B}$ & $p$ & $B$ & $p$ \\
\hline Preoperative EF & 0.54 & $\leq 0.001$ & 0.49 & $\leq 0.001$ & 0.44 & $\leq 0.001$ & 0.52 & $\leq 0.001$ \\
\hline Occupation & 0.31 & 0.02 & & & 0.32 & 0.02 & 0.29 & 0.02 \\
\hline Diabetes & -0.25 & 0.03 & & & & & -0.24 & 0.03 \\
\hline Hypertension & -0.28 & 0.009 & -0.33 & 0.004 & -0.31 & 0.005 & -0.31 & 0.006 \\
\hline Smoking & -0.53 & 0.001 & -0.42 & 0.01 & -0.42 & 0.01 & -0.41 & 0.02 \\
\hline Peripheral vascular disease (PVD) & -0.53 & 0.05 & -0.81 & 0.005 & -0.62 & 0.03 & -0.76 & 0.008 \\
\hline Gastrointestinal disease & & & -0.39 & 0.02 & & & & \\
\hline Angina grade & & & & & & & 0.20 & 0.02 \\
\hline Constant & 0.445 & & 0.179 & & 0.123 & & 0.316 & \\
\hline$R^{2}$ & 0.21 & & 0.19 & & 0.17 & & 0.20 & \\
\hline F & 6.094 & & 5.461 & & 4.694 & & 5.676 & \\
\hline$P$ & $\leq 0.001$ & & $\leq 0.001$ & & $\leq 0.001$ & & $\leq 0.001$ & \\
\hline
\end{tabular}

Coding of variables included in the model:

0 was given for not working, no PVD, no smoking, no diabetes, no gastrointestinal disease, low angina class (CCS1-CCS2), and EF $\geq 40 \%$

1 was given for working, PVD, smoking, diabetes, presence of gastrointestinal disease, high angina class (CCS3-CCS4), and EF < 40\% 
for German version [13]. But much higher than 0.80 of the Turkish version [14].

The present study found a statistically significant improvement in all domains of QOL after 3 and 6 months of CABG. Physical and social domains exhibited the greatest improvement with the smallest improvement in the emotional one after 6 months of surgery. This is in agreement with a previous study reported in Greece [15]. This may be due to CABG has a greater influence on physical functioning as well as a decrease of symptoms, and consequently, a better living with this condition. But in contrast, a study conducted in Holland showed a decline in HRQOL 6 months after CABG surgery [16]. This could be explained by the effect of anxiety and depression in CABG patients.

The current finding indicated that male patients were one of the significant predictors of all domains of QOL post 3 months of surgery. The reason for that result is that the majority of female patients were older age, not working, had multiple diseased vessels, lower preoperative scores in all domains of QOL, and had multiple comorbidities. This is in line with previous findings reported in Pakistan and Belgrade [17, 18]. But, two Iranian studies found no significant association between sex and change in QOL scores $[19,20]$. Also, the rural residence was an independent predictor of all domains of QOL post 3 months of surgery. Similarly, a previous study in France found the same results [21]. This could be attributed to more physical activity, less life stress, or a better lifestyle of rural patients compared to urban inhabitants.

The present study showed that education and occupation were one of the independent predictors for higher social QOL domains after 3 and 6 months of surgery, respectively. Such results agree with a previous study conducted in France [21]. This might be explained by that educated persons maintain their lifestyle, health-related behavior, and consider the essence of their illness and surgery complications. Also, strong financial security may help patients to survive more easily after surgery and get better QOL by avoiding negative feelings and self-criticism that their physical, mental, and social health could be seriously impacted. However, an Iranian study [22] contradicts such results.

The present study found that severe angina (CCS3CCS4) after 6 months of surgery was one of the independent predictors of improving QOL in the global domain. That result was consistent with a Belgrade study [18]. While a French study [23] disagreed with that finding.

The current study found high-grade dyspnea class (NYHA3-NYHA4) after 3 months of surgery was one of the independent predictors of increasing QOL in the social domain. This is in line with research conducted in Serbia [24]. This may be clarified by the fact that CABG has a stronger effect on dyspnea relief. Also, the current study showed that hypercholesterolemia and hypertension were significant predictors of QOL worsening after 3 months of CABGs in all domains of QOL. This agrees with a study conducted in Serbia [24] and the USA [25]. This could be explained that hypertensive patients might be controlled with drugs that could influence QOL after surgery and complicated by other chronic diseases.

The current study showed that diabetes was one of the significant independent predictors of QOL worsening in the physical domain after 6 months of surgery. This is concordant with a study reported in France [21]. On the other hand, a previous study in Iran [22] found higher QOL in diabetic patients than non-diabetic ones.

The present study showed that smoking was one of the significant predictors of QOL worsening in all domains after 3 and 6 months of surgery. This is in harmony with previous studies in the UK [26] and the USA [25]. It could be explained that smoking is potentially modifiable and related to a broad spectrum of an undesirable outcomes.

The present study found that peripheral vascular disease (PVD) significantly impaired QOL after 6 months of surgery in all domains of QOL. This finding agrees with a previous study in the USA [25].

The present finding showed that cerebrovascular disease and renal disease were one of the significant predictors of QOL worsening in the social domain of QOL after 3 months of surgery. Similarly, previous studies reported in the USA [25, 27], respectively.

The present study indicated that patients with gastric problems were one of the independent predictors of all domains of QOL after 3 months of surgery and only emotional domain after 6 months of surgery. This agrees with a previous study in the UK [28].

The current study showed a significantly higher improvement in all QOL domains after 6 months of surgery in patients with low $\mathrm{EF}<40 \%$. This is consistent with a study conducted in Finland [29]. This could be explained that patients regained their QOL, and relieved from their physical, emotional, and social difficulties due to enhanced function of the left ventricle. On the other hand, previous researches in the USA [25] and Belgrade [18] disagreed with these results.

The present study found that increasing age was a significant independent predictor of improving emotional difference QOL domain after 3 months of surgery. This is similar to studies conducted in the USA [25] and Finland [29]. The possible explanation is that old patients suffer from severe physical, emotional, and social constraints before surgery, and CABG surgery could be performed with tolerable morbidity, mortality, and with 
a significant enhancement in functional, emotional, and social status of elderly.

\section{Study limitations and strengths}

Although this study is a prospective single-center one and its results cannot be generalized at the national level, it contains patients from a high-volume referral cardiac center, which is a major advantage. The study is one of the very few QOL studies reported in Egypt and the Arab world in the cardiac surgery spectrum. It covers a research gap that an important limitation in the current use of HRQOL tools in cardiac surgery and it has a prospective nature. The patients were followed up for 6 months postoperatively by telecommunications using mobile phones, which are the major advantage. This study is the first Arabic and Egyptian study to construct and validate the MacNew heart disease questionnaire in its newly translated Arabic form. Also, it will change the practice in cardiac surgery. This study will give a background to the cardiac surgeons on how to choose their patients in a good way before the operation, including this will reflect on reducing mortality and morbidity rates and increasing focus on QOL.

\section{Conclusion}

CABG surgery has a positive effect on QOL with significant improvement in all domains of QOL after surgery, especially the physical and social scores. Male sex, rural residence hypercholesterolemia, and hypertension are significant independent predictors of QOL in all domains of QOL 3 months after surgery. Low EF $<40 \%$ is the strongest predictor of QOL improvement in all domains after 6 months of surgery.

The Arabic version of the MacNew questionnaire is recommended for assessing health-related quality of life in Arabic-speaking patients with IHD or patients undergoing CABG. Nationwide longitudinal studies are needed to assess changes in QOL after CABG over longer intervals.

\section{Supplementary information}

Supplementary information accompanies this paper at https://doi.org/10. 1186/s43057-020-00028-x.

Additional file 1. Arabic version of McNew Questionaire

Additional file 2. Modified MacNew QLMI (Valenti etal., 1996)

\section{Abbreviations}

CABG: Coronary artery bypass graft surgery; CHD: Coronary heart disease; COP: Cardiac output; ECHO: Echocardiography; EF: Ejection fraction; HRQOL: Health-related quality of life; ICU: Intensive care unit; IDF. Normal: Inverse distribution function. Normal.; IHD: Ischemic heart disease; IRB: Institutional Research Board; LITA: Left internal thoracic artery; LVED D: Left ventricular end diastolic diameter; LVESD: Left ventricular end systolic diameter; NYHA: New York Heart Association; PVD: Peripheral vascular disease; PROs: Patient-reported outcomes; QOL: Quality of life;
SPSS: Statistical package of social sciences; SVG: Saphenous vein graft; USA: Unites States of America

\section{Acknowledgements}

We would like to thank the patients, staff members of the Institute for their cooperation and the director of the Institute for accepting this work.

\section{Authors' contributions}

MA conducted the literature search, performed the data collection and interpretation of the data, and drafted the manuscript. WA, AG, and OF supervised the study and conducted the review of data, involved in the study design, analyzed and interpreted the data, and drafted the manuscript. SM designed the study, analyzed and interpreted the data, and drafted the manuscript. NA was one of the supervisors of the research. All authors have read and approved the final manuscript.

\section{Funding}

No funding was received, self-funded.

\section{Availability of data and materials}

The datasets used and/or analyzed during the current study available from the corresponding author on reasonable request.

\section{Ethics approval and consent to participate}

The study conformed to the principles outlined in the Declaration of Helsinki. An official approval was obtained from Institutional Research Board (IRB), Faculty of Medicine, Mansoura University (MUIRB-81-780-2) and the Director of Nasser Institute Hospital for conducting the study (NIRT-2/5/17). Patients were informed and signed written consents for participation in the study and operation.

\section{Consent for publication}

Patients were informed and signed written consents for publishing of clinical data.

\section{Competing interests}

The authors declare that they have no competing interests.

\section{Author details}

${ }^{1}$ Department of Cardiothoracic Surgery, National Heart Institute, Cairo, Egypt. ${ }^{2}$ Department of Cardiothoracic Surgery, Shebein Elkom Teaching Hospital, Shebein Elkom, Egypt. ${ }^{3}$ Department of Public Health and Preventive Medicine, Faculty of Medicine, Mansoura University, Mansoura, Egypt. ${ }^{4}$ Department of Cardiothoracic Surgery, Faculty of Medicine, Mansoura University, Mansoura, Egypt.

Received: 22 April 2020 Accepted: 24 July 2020

Published online: 01 September 2020

\section{References}

1. Barzin M, Mirmiran P, Afghan M, Azizi F (2011) Distribution of 10-year risk for coronary heart disease and eligibility for therapeutic approaches among Tehranian adults. Public Health 125(6):338-344

2. Hillis LD, Smith PK, Anderson JL, Bittl JA, Bridges CR, Byrne JG et al (2011) 2011 ACCF/AHA guideline for coronary artery bypass graft surgery: a report of the American College of Cardiology Foundation/American Heart Association task force on practice guidelines developed in collaboration with the American Association for Thoracic Surgery, Society of Cardiovascular Anesthesiologists, and Society of Thoracic Surgeons. J Am Coll Cardiol 58(24):e123-e210

3. Haraldstad K, Wahl A, Anden R, Andersen JR, Andersen MH, Beisland E et al (2019) A systematic review of quality of life research in medicine and health sciences. Qual Life Res 28:2641-2650

4. Higginson IJ, Carr AJ (2001) Measuring quality of life: using quality of life measures in the clinical setting. BMJ 322(7297):1297-1300

5. Tully PJ (2013) Quality-of-life measures for cardiac surgery practice and research: a review and primer. J Extra Corpor Technol 45(1):8-15

6. Hofer S, Saleem A, Stone J, Thomas R, Tulloch H, Oldridge N (2012) The MacNew heart disease health-related quality of life questionnaire in patients with angina and patients with ischemic heart failure Value Health 15:143-150 
7. Von Elm E, Altman DG, Egger M, Pocock SJ, Gøtzsche PC, Vandenbroucke JP et al (2014) The strengthening the reporting of observational studies in epidemiology (STROBE) statement: guidelines for reporting observational studies. Inter J Surg 12(12):1495-1499

8. Valenti L, Lim L, Heller RF, Knapp J (1996) An improved questionnaire for assessing quality of life after acute myocardial infarction. Quality of Life Res 5(1):151-161

9. Templeton GF (2011) A two-step approach for transforming continuous variables to normal: implications and recommendations for IS research. Commun Assoc Inf Syst 28(1):4. https://aisel.aisnet.org/cais/vol28/iss1/4. https://doi.org/10.17705/1CAIS.02804

10. Pavya B, lliou M, Höferc $S$, Vergès-Patois $B$, Coronee $S$, Aeberhard $P$ et al (2015) Validation of the French version of the MacNew heart disease healthrelated quality of life questionnaire. Arch Cardiovasc Dis 108:107-117

11. Alphin S, Hofer S, Perk J, Slørdahl S, Zwisler AO, Oldridge N (2015) The MacNew heart disease health-related quality of life questionnaire: a Scandinavian validation study. Soc Indic Res 122:519-537

12. Kang K, Gholizadeh L, Inglis SC, Han HR (2019) Validation of the Korean version of the MacNew heart disease health-related quality of life questionnaire. J Nurs Res 27(2):e11. https://doi.org/10.1097/jnr. 0000000000000274

13. Gramm L, Farin E, Jaeckel WH (2012) Psychometric properties of the German version of the MacNew heart disease health-related quality of life questionnaire. Health Qual Life Outcomes 10:83

14. Daskapan A, Höfer S, Oldridge N, Alkan N, Muderrisoglu H, Tuzun EH (2008) The validity and reliability of the Turkish version of the MacNew heart disease questionnaire in patients with angina. J Eval Clin Pract 14:209-213

15. Merkouris A, Apostolakis E, Pistolas D, Papagiannaki V, Diakomopoulou E, Patiraki E (2009) Quality of life after coronary artery bypass graft surgery in the elderly. Eur J Cardiovasc Nurs 8(1):74-81

16. Middel B, El Baz N, Pedersen SS, van Dijk JP, Wynia K, Reijneveld SA (2014) Decline in health-related quality of life 6 months after coronary artery bypass graft surgery: the influence of anxiety, depression, and personality traits. J Cardiovasc Nurs 29(6):544-554

17. Barolia R, Ali F, Jaffar S, Sami S (2012) Coronary artery bypass grafting: quality of life of patients in Karachi. British J Nursing 21(6):349-355

18. Peric V, Stolic R, Jovanovic A, Grbic R, Lazic B, Sovtic S, Borzanovic M (2017) Predictors of quality of life improvement after 2 years of coronary artery bypass surgery. Ann Thorac Cardiovasc Surg 23(5):233-238

19. Rankin S (1990) Differences in recovery from cardiac surgery: a profile of male and female patients. Heart Lung 19:481-448

20. King KM, Collins-Nakai RL (1998) Short term recovery from cardiac surgery in women: suggestions for practice. Can J Cardiol 14:1367-1371

21. Perrotti A, Ecarnot F, Monaco F, Dorigo E, Monteleone P, Besch G et al (2019) Quality of life 10 years after cardiac surgery in adults: a long-term follow-up study. Health Qual Life Outcomes 17(1):88

22. Najafi M, Sheikhvatan M, Montazeri A (2009) Quality of life-associated factors among patients undergoing coronary artery bypass surgery as measured using the WHOQOL-BREF. Cardiovasc J Africa 20(5):284

23. Falcoz PE, Chocron S, Stoica L, Kaili D, Puyraveau M, Mercier M et al (2003) Open heart surgery: one-year self-assessment of quality of life and functional outcome. Ann Thorac Surg 76(5):1598-1604

24. Peric V, Borzanovic M, Stolic R, Jovanovic A, Sovtic S, Dimkovic S et al (2008) Predictors of worsening of patients' quality of life six months after coronary artery bypass surgery. J Card Surg 23(6):648-654

25. Rumsfeld JS, Ho PM, Magid DJ, McCarthy M Jr, Shroyer ALW, MaWhinney S et al (2004) Predictors of health-related quality of life after coronary artery bypass surgery. Ann Thorac Surg 77(5):1508-1513

26. Lindsay GM, Hanlon P, Smith LN, Wheatley DJ (2000) Assessment of changes in general health status using the short-form 36 questionnaire 1 year following coronary artery bypass grafting. Eur J Cardio Thoracic Surg 18(5):557-564

27. Parikh CR, Coca SG, Smith GL, Vaccarino V, Krumholz HM (2006) Impact of chronic kidney disease on health-related quality-of-life improvement after coronary artery bypass surgery. Arch Internal Med 166(18):2014-2019

28. Al-Ruzzeh S, Athanasiou T, Mangoush O, Wray J, Modine T, George S et al (2005) Predictors of poor mid-term health related quality of life after primary isolated coronary artery bypass grafting surgery. Heart 91(12):1557-1562

29. Järvinen O, Saarinen T, Julkunen J, Huhtala H, Tarkka MR (2003) Changes in health-related quality of life and functional capacity following coronary artery bypass graft surgery. Eur J Cardio Thorac Surg 24(5):750-756

\section{Publisher's Note}

Springer Nature remains neutral with regard to jurisdictional claims in published maps and institutional affiliations.

\section{Submit your manuscript to a SpringerOpen ${ }^{\circ}$ journal and benefit from:}

- Convenient online submission

- Rigorous peer review

- Open access: articles freely available online

- High visibility within the field

- Retaining the copyright to your article

Submit your next manuscript at $\boldsymbol{\nabla}$ springeropen.com 